\title{
Spatial sensitivity of species habitat patterns to scenarios of land use change (Switzerland)
}

\author{
Janine Bolliger · Felix Kienast $\cdot$ Reto Soliva • \\ Gillian Rutherford
}

Received: 2 March 2006/ Accepted: 16 January 2007/Published online: 6 March 2007

(C) Springer Science+Business Media B.V. 2007

\begin{abstract}
Long-term societal trends which include decreasing population in structurally poorer regions and changes in agricultural policies have been leading to land abandonment in various regions of Europe. One of the consequences of this development includes spontaneous forest regeneration of formerly open-land habitats with likely significant effects on plant and animal diversity. We assess potential effects of agricultural decline in Switzerland $\left(41,000 \mathrm{~km}^{2}\right)$ and potential impacts on the spatial distribution of seven open-land species (insects, reptile, birds) under land-use change scenarios: (1) a businessas-usual scenario that extrapolates trends observed during the last 15 years into the future, (2) a liberalisation scenario with limited regulation, and (3) a lowered agricultural production scenario fostering conservation. All scenarios were developed in collaboration with socioeconomists. Results show that spontaneous reforestation is potentially minor in the lowlands since combinations of socio-economic (better accessibility), topographic (less steep slopes), and climatic factors (longer growing seasons) favour agricultural use and make land abandonment
\end{abstract}

J. Bolliger $(\bowtie) \cdot$ F. Kienast · R. Soliva ·

G. Rutherford

Swiss Federal Research Institute WSL, Zürcherstrasse

111, CH-8903 Birmensdorf, Switzerland

e-mail: janine.bolliger@wsl.ch less likely. Land abandonment, spontaneous reforestation, and subsequent loss of open-land, however, are potentially pronounced in mountainous areas except where tourism is a major source of income. Here, socio-economic and natural conditions for cultivation are more difficult, leading to higher abandonment and thus reforestation likelihood. Evaluations for openland species core habitats indicate pronounced spatial segregation of expected landscape change. Habitat losses (up to 59\%) are observed throughout the country, particularly at high elevation sites in the Northern Alps. Habitat gains under the lowered agricultural production scenario range between 12 and $41 \%$ and are primarily observed for the Plateau and the Northern Alps.

Keywords Agricultural decline - Habitat suitability maps - Species habitat distribution modelling - Scenarios of land use change · Switzerland

\section{Introduction}

Land-use change is primarily driven by socioeconomic factors and significantly governs landscape structure, function, and dynamics (Wu and Hobbs 2002; Wu 2006). Land-use change has recently been identified to be a key research area in landscape ecology (Wu and Hobbs 2002). 
The economic significance of agriculture has decreased in many parts of Europe over the last decades (Labaune and Magnin 2002; Dirnböck et al. 2003; Dullinger et al. 2003a; Laiolo et al. 2004; van der Vaart 2005). This trend has been prominent in mountainous areas since the 1950's (Meeus et al. 1991; Bätzig 1996). Primary drivers for this development are of socio-economic nature (e.g., globalisation and mechanisation). Consequences include reforestation of formerly open land. Although reforestation may lead to a short-term increase of species richness due to increased landscape structure (Söderström et al. 2001), effects of pastoral abandonment may cause habitat losses of open land species (Labaune and Magnin 2002; Dirnböck et al. 2003; Dullinger et al. 2003a) and potentially constitute a threat for species diversity (Tilman et al. 2001; Dullinger et al. 2003b). Thus, policies for maintaining openland environments to preserve species diversity are needed if the maintenance of landscape and plant-animal diversity is a priority (Bakker 1989; Söderström et al. 2001). This requires detailed understanding of the relationships between biota and their environments to ensure that the ecological characteristics of value to wildlife assemblages are maintained (McCracken and Bignal 1998; Lundström-Gilliéron and Schläpfer 2003).

It has been claimed that more research is needed to identify processes and consequences of land use change and foster collaboration between research areas beyond ecology to ensure truly inter- and trans-disciplinary science ( $\mathrm{Wu}$ and Hobbs 2002). This study is an outcome of an interdisciplinary research project in which socioeconomic experts constructed conservation and agricultural policy scenarios. We investigate landuse change (agricultural decline) as a process with drivers that encompass policy options, societal opinions and interests including agricultural, environmental, and socio-economic factors to benchmark potential consequences on species distributions using land-use change scenarios. Potential effects of the scenarios are inferred on seven open-land animal species. The species include butterflies (Erebia aethiops, Melanargia galathea, Lysandra bellargus), grasshoppers (Chorthippus scalaris), birds (Alauda arvensis, Saxicola rubetra), and reptiles (Lacerta vivipara), whose distribution data were available for Switzerland $\left(41,000 \mathrm{~km}^{2}\right)$. The scenarios include (1) business as usual, (2) liberalisation, and (3) lowered agricultural production. For our scenarios, two socio-economic drivers were identified which jointly influence land-use: societal support (state/federal subsidies) to agriculture and societal support to conservation. The business as usual scenario extrapolates trends derived from landuse changes during 1985-1997 into the future. The scenario "lowered agricultural production" optimises non-intensively used open land but allows natural reforestation in marginal areas since depopulation is an ongoing process even in heavily subsidised areas. The liberalisation scenario relies on the assumption that no public support is given to both agriculture and conservation and that the agricultural markets are fully liberalised following WTO requirements.

We address the following questions: what are the potential landscape-pattern changes under scenarios of land-use change? What are likely magnitudes and spatial distribution patterns of change for selected open-land species?

\section{Materials and methods}

Study area

Switzerland covers ca. 41,000 $\mathrm{km}^{2}$ (Statistisches Jahrbuch der Schweiz 1997). The climate is temperate humid. Conditions vary regionally due to the mountainous influence and range from intra-alpine dry and continental climate regime (Central Alps) to oceanic high elevation (Northern Alps, Jura Mountains) and low-elevation climate (Plateau). The southern Alps in Switzerland are dominated by an insubrian climate type with relatively mild and dry winters and warmhumid summers (Fig. 1).

Analysis concept

The analysis consists of three steps (Fig. 2a-c). First, scenarios of land-use change based on socio-economic considerations were developed and spatially implemented (Fig. 2a). Then, habitat suitability models were developed for seven 
Fig. 1 Biogeographic regions of Switzerland

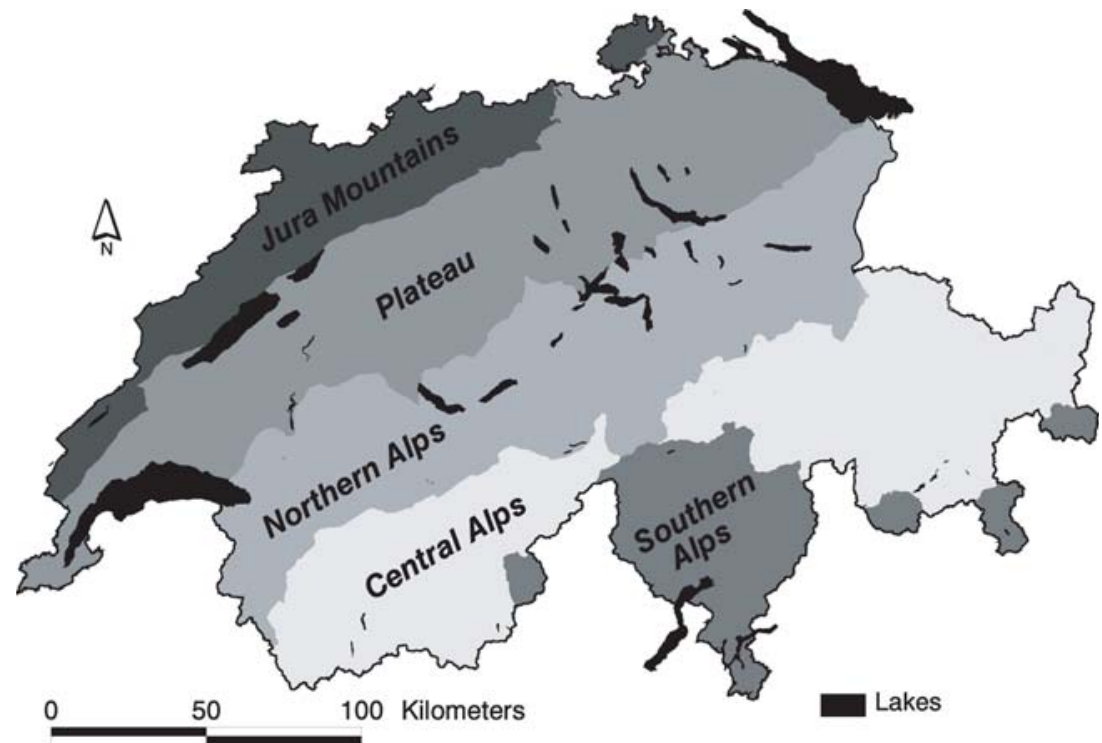

animal species requiring open-land habitats (Fig. 2b). Third, likely areas and the magnitude of scenario-induced change were identified by intersecting the predicted core areas of species habitats with the scenarios (Fig. 2c).

\section{Identifying scenarios}

As agriculture in Switzerland is highly subsidised (OECD 2002; BLW 2004), public support to agriculture is the major driver for extent and rate of agricultural decline. Based on recent trends and possible future developments in agricultural and conservation policies (Flury 2002; Mack and Ferjani 2002; BLW 2003, 2004; Weibel 2004) we identified main drivers that influence the decisions of land managers, e.g., direct payments to farmers, agri-environmental regulations, or product prices of conventional food products. We made qualitative assumptions how these drivers might vary under each scenario, leading from international and national policy drivers to local land use consequences (Fig. 3).

\section{Business as usual}

Current trends of structural changes in agriculture will continue into the future as observed for the recent past. Decreasing market interventions will lead to lower product prices that gradually approach the EU-level, whereas the level of costs is not expected to change significantly (Flury

$$
\begin{aligned}
& \text { a) Land-use/land-cover change scenarios } \\
& \text { 1) Socio-economic scenario identification } \\
& \text { 1.1) Business as usual } \\
& \text { 1.2) Liberalisation } \\
& \text { 1.3) Lowered agricultural production (moderate) } \\
& \text { 1.4) Lowered agricultural production (strong) } \\
& \text { 2) Spatial scenario implementation }
\end{aligned}
$$

\section{b) \\ Species habitat suitability models}

Development of spatially explicit habitat distribution models for seven animal species requiring open-land habitats

\section{c)}

Identifying potential sensitive core areas for species habitat changes

Intersection of the land-use/land-cover change scenarios with the potential core habitats of the individual species

Fig. 2 Concept of analysis 


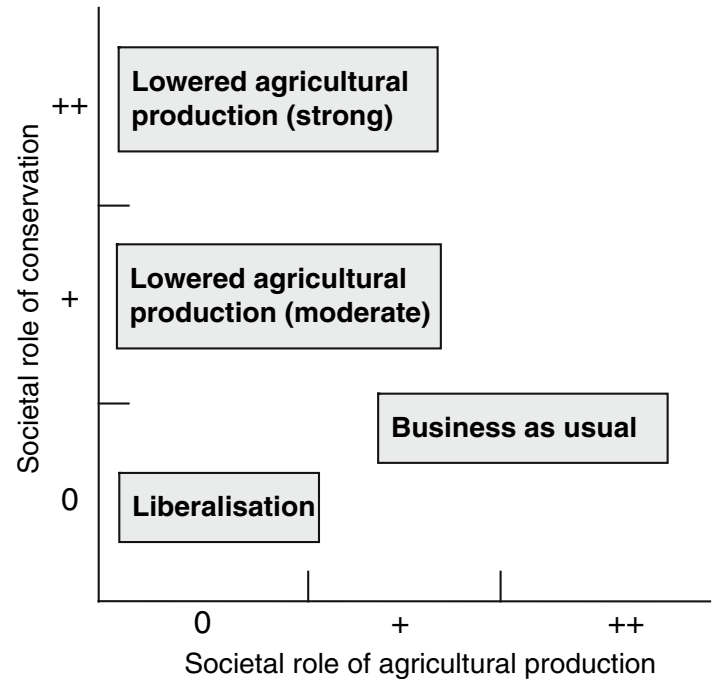

Fig. 3 Socio-economic concept to develop scenarios of land-use change: business as usual, liberalisation, lowered agricultural production (moderate, strong)

2002). Ecological direct payments and income from conservation contracts, however, are likely higher because society increasingly demands semi-natural cultural landscapes for recreation. Following the trend towards a more environmentfriendly agriculture, agri-environmental regulations are expected to be stricter. Structural change in agriculture is assumed to continue at the present rate, leading to a moderate increase in abandoned land.

\section{Liberalisation}

This scenario suggests liberalised agricultural markets as a result of WTO requirements with no state support of agriculture or conservation and agri-environmental regulations. Product prices are expected to be much lower than today. Since neither state nor society are interested in supporting agriculture or conservation, demand for more expensive organic or label products is likely to be lower than today.

Given that maintenance of agriculture strongly depends on state support (FAT 2002) most mountain farms are likely abandoned in the future. Thus, the majority of mountainous openland is assumed to become abandoned and reforested except for areas close to larger settlements.
Easily accessible and fertile land in the climatically favoured lowlands is assumed to be more intensively used than today.

\section{Lowered agricultural production}

This scenario relies on a strong conservation policy under a liberalised agricultural market as a result of WTO requirements and general globalisation. Society subsidises conservation and agrobiodiversity stronger than today. Conservation outweighs food production, which focuses on organic and other labelled products. Ecological direct payments tied to tight agri-environmental regulations and contributions for individual conservation contracts are increased. Land-use requirements determined by state agri-environmental planning agencies are optimised for conservation. A large proportion of the land is thus likely to be managed by "biodiversity and landscape managers" rather than by farmers.

Spatial scenario implementation

\section{Land-use data}

We used land-use data for two time steps (19791985, 1992-1997) for Switzerland (BFS 1979/85; BFS 1992/97). The original land-use data are derived from aerial photographs at a $100 \mathrm{~m}$ resolution, categorised into 74 classes. Of the original 74 classes, 20 were aggregated into 5 classes and the remaining 54 were classed as "Other", yielding six classes: forest, open forest, scrub, non-intensively used open land, intensively used open land, other (Table 1). The aggregation of the land-use categories relied on criteria such as height of vegetation, percentage crown cover, the presence of woody species and for the agricultural classes, whether use was year-round and the land was machine-accessible. Open forest is a mixture of agricultural and non-agricultural land, which is not always possible to distinguish from aerial photographs (Sager and Finger 1992). 'Hedges and Groves' was retained in the closed canopy forest class, due both to our height/cover criteria and because this land-cover class acts as a potential seed source as much as the other classes within closed canopy forest. 
Table 1 Land-use categories for scenario development

\begin{tabular}{|c|c|c|}
\hline Aggregated class & Original classes & Description \\
\hline Forest & $\begin{array}{l}\text { Forest } \\
\text { Normal forest } \\
\text { Strips, blocks } \\
\text { Bushes } \\
\text { Groves, hedges }\end{array}$ & $\begin{array}{l}\text { Vegetation height }>3 \mathrm{~m} \\
\text { Density }>60 \% \\
\text { Composed of tree species }\end{array}$ \\
\hline Open forest & $\begin{array}{l}\ldots \text { on non-agriculturally used land } \\
\ldots \text { on agriculturally used land } \\
\text { Groups of trees on agriculturally used land } \\
\text { Other groves }\end{array}$ & $\begin{array}{l}\text { Vegetation height }>3 \mathrm{~m} \\
\text { Density } 20-60 \% \\
\text { Composed of tree species }\end{array}$ \\
\hline Scrub & $\begin{array}{l}\text { Overgrown meadows } \\
\text { Overgrown alpine pasture } \\
\text { Shrubs, bushes }\end{array}$ & $\begin{array}{l}\text { Vegetation height }<3 \mathrm{~m} \\
\text { Density }>50 \%\end{array}$ \\
\hline Non-intensive open land & $\begin{array}{l}\text { Pasture in vicinity of settlements } \\
\text { Hay alps, mountain meadows } \\
\text { Sheep alps } \\
\text { Favourable to pasturing } \\
\text { Stony alpine pasture } \\
\text { Grass, herb vegetation }\end{array}$ & $\begin{array}{l}\text { Used for grazing } \\
\text { Use not necessarily year-round } \\
\text { Not machine-accessible }\end{array}$ \\
\hline Intensive open land & $\begin{array}{l}\text { Machine accessible meadows } \\
\text { Meadows, limited machine access }\end{array}$ & $\begin{array}{l}\text { Year-round use } \\
\text { In the vicinity of settlements } \\
\text { Mown }\end{array}$ \\
\hline Other & Settlement, rock & \\
\hline
\end{tabular}

\section{Spatially explicit transitions}

Transition probabilities were derived from GLMs (General Linear Models). We used a logit link function to relate land-use change between 1985 and 1997 to various variables (e.g., topography, slope, composition of the surrounding neighbourhoods). For each land-use transition a logistic regression model was calibrated for the land-use categories forest, open forest, scrub, non-intensively used and intensively used open land. The transition probabilities yield the probability of any pixel with land-use type $\mathrm{x}$ to be transformed to land-use type y under given constraints. The predicted response surfaces take values of probability of change between 0 and 1 .

\section{Magnitude of change}

The magnitude of land-use change is the number of pixels, which switched to another category between 1985 and 1997 (BFS 1979/85; BFS 1992/ 97). The inferred magnitude of change depends on the scenario and is determined on the basis of socio-economic judgment (Table 2a-e).
The business as usual scenario assumes a continuation of observed changes in land-use for 1985-1997. The magnitude of change is thus the same as observed between 1985 and 1997 (Table 2a).

The liberalisation scenario was subdivided into two variants: lowlands (<900 m asl) (Table 2b), mountain tourist areas ( $>900 \mathrm{~m}$ asl) (Table 2c). No forest changes are assumed in the lowlands and in important mountain tourist resorts as these areas are likely to remain settled and managed due to higher infrastructure availability and easy accessibility. A tourist resort is defined as more than 30,000 overnight guests in 1998. For mountain regions, the liberalisation scenario assumes a high percentage of pixels transforming from scrub and open forest to closed forest. In the lowlands an almost complete transformation of agriculture from nonintensively to intensively used open land is assumed (Table 2b, c).

Both variants of the lowered agricultural production scenario (moderate and strong) assume transformation of intensive to non-intensive agriculture, allowing changes in forest cover due to 
Table 2 Transition frequencies

\begin{tabular}{|c|c|c|c|c|c|}
\hline \multirow[t]{2}{*}{ From } & \multicolumn{5}{|l|}{ To } \\
\hline & $\begin{array}{l}\text { Forest } \\
(\%)\end{array}$ & $\begin{array}{l}\text { Open forest } \\
(\%)\end{array}$ & $\begin{array}{l}\text { Scrub } \\
(\%)\end{array}$ & $\begin{array}{l}\text { Non-intensive } \\
\text { open land }(\%)\end{array}$ & $\begin{array}{l}\text { Intensive } \\
\text { open land (\%) }\end{array}$ \\
\hline \multicolumn{6}{|l|}{ (a) Business as usual } \\
\hline Closed forest & 99 & $<0.5$ & $<0.5$ & $<0.5$ & $<0.5$ \\
\hline Open forest & 8 & 90 & $<0.5$ & 1.5 & 0.7 \\
\hline Scrub & 8 & 4 & 87 & 0.8 & $<0.5$ \\
\hline Non-intensive open land & $<0.5$ & 0.6 & 1.6 & 97 & 0.6 \\
\hline Intensive open land & $<0.5$ & $<0.5$ & $<0.5$ & 2.5 & 97 \\
\hline \multicolumn{6}{|c|}{ (b) Liberalisation (lowlands ( $<900 \mathrm{~m}$ asl), tourist areas) } \\
\hline Closed forest & 100 & 0 & 0 & 0 & 0 \\
\hline Open forest & 0 & 100 & 0 & 0 & 0 \\
\hline Scrub & 0 & 0 & 100 & 0 & 0 \\
\hline Non-intensive open land & 0 & 0 & 5 & 15 & 80 \\
\hline Intensive open land & 0 & 0 & 0 & 10 & 90 \\
\hline \multicolumn{6}{|c|}{ (c) Liberalisation (mountains $>900 \mathrm{~m}$ asl) } \\
\hline Closed forest & 100 & 0 & 0 & 0 & 0 \\
\hline Open forest & 80 & 20 & 0 & 0 & 0 \\
\hline Scrub & 80 & 10 & 10 & 0 & 0 \\
\hline Non-intensive open land & 30 & 40 & 20 & 10 & 0 \\
\hline Intensive open land & 0 & 45 & 40 & 10 & 5 \\
\hline \multicolumn{6}{|c|}{ (d) Lowered agricultural production (moderate) } \\
\hline Closed forest & 100 & 0 & 0 & 0 & 0 \\
\hline Open forest & 0 & 100 & 0 & 0 & 0 \\
\hline Scrub & 0 & 5 & 95 & 0 & 0 \\
\hline Non-intensive open land & 0 & 0 & 5 & 95 & 0 \\
\hline Intensive open land & 0 & 10 & 10 & 20 & 60 \\
\hline \multicolumn{6}{|c|}{ (e) Lowered agricultural production (strong) } \\
\hline Closed forest & 100 & 0 & 0 & 0 & 0 \\
\hline Open forest & 0 & 90 & 10 & 0 & 0 \\
\hline Scrub & 0 & 5 & 95 & 0 & 0 \\
\hline Non-intensive open land & 0 & 0 & 5 & 95 & 0 \\
\hline Intensive open land & 0 & 20 & 20 & 40 & 20 \\
\hline
\end{tabular}

ongoing depopulation of marginal areas at high elevations (Table 2d, e).

\section{Deriving scenario maps}

Scenario maps with the locations of the inferred changes were generated by combining the spatially explicit transition probabilities with the scenario-specific magnitude of change. Pixels subject to change were selected in the following way: transition probabilities of a given transition were sorted in descending order. Then, pixels were chosen in descending order until the scenario-dependent pixel frequency per land-use category was reached. The "newly generated" land-use pixels were not allowed any further transformation.
Quantifying landscape patterns

Landscape metrics (FRAGSTATS (McGarigal et al. 2002)) were calculated to quantify the landscape change resulting from the land-use scenarios. Landscape composition was assessed using number of patches, mean patch size, and diversity. Landscape configuration was quantified by an aggregation index (McGarigal et al. 2002).

Species habitat distribution models

Spatial probability surfaces for animal species were calculated based on species presence/absence based on GLMs (logit link) and as a function of land-use and climatic variables. 
Biotic dependent variables

Seven animal species were chosen as biotic dependent variables (Table 3). Requirements for species selection were sensitivity to open-land habitats and satisfying data availability for the whole country. Insects, reptile, and butterfly data were derived from the Centre Suisse de la Faune (CSCF), Neuchâtel, Switzerland. Bird data was obtained from the Swiss Ornithological Institute, Sempach, Switzerland.

Skylark (Alauda arvensis, L. 1758) and whinchat (Saxicola rubetra, L. 1758) are birds preferring non intensive land-use and varied vegetation (Orlowski 2004; Jepsen et al. 2005; Moreira et al. 2005; Muller et al. 2005).

In Switzerland, the syklark's main distribution range encompasses the western and northern Plateau between 400 and $700 \mathrm{~m}$ asl (Schmid et al. 1998). Increasing intensification of agricultural areas and insecticides have significantly weakened the populations (Jenny 1990; Tucker and Heath 1994). Whinchats inhabit non-intensive meadows with low mowing frequencies (Schmid et al. 1998) and are primarily observed between 1200 and $2000 \mathrm{~m}$ asl (Schmid et al. 1998). Whinchats are largely missing from the northern Jura mountains and the Plateau where agriculture has intensified (Schmid et al. 1998).

Three butterfly species are considered. Scotch Argus (Erebia aethiops, Esper 1777) is widely distributed including non-intensive meadows and fields in the lowlands ( $400 \mathrm{~m}$ asl) to subalpine

Table 3 Species data: species absences assessed empirically $\left({ }^{++}\right)$, by experts $\left(^{+}\right)$

\begin{tabular}{lccc}
\hline & \multicolumn{3}{c}{ Number of observations } \\
\cline { 2 - 4 } & Presence & Absence & Total \\
\hline Aves & 963 & $1683^{++}$ & 2646 \\
$\begin{array}{l}\text { Alauda arvensis } \\
\text { Saxicola rubetra }\end{array}$ & 443 & $2203^{++}$ & 2646 \\
$\begin{array}{l}\text { Reptilia } \\
\text { Lacerta vivipara }\end{array}$ & 1484 & $2345^{+}$ & 3829 \\
$\begin{array}{l}\text { Lepidoptera } \\
\text { Erebia aethiops }\end{array}$ & 543 & $9818^{+}$ & 10361 \\
$\begin{array}{l}\text { Melanargia galathea } \\
\text { Lysandra bellargus }\end{array}$ & 1627 & $6408^{+}$ & 8035 \\
Saltatoria & 820 & $5867^{+}$ & 6687 \\
Chorthippus scalaris & 935 & $3957^{+}$ & 4892 \\
\hline
\end{tabular}

meadows (2000 m asl) (Gonseth 1987). The species is threatened on the Plateau (Gonseth 1987). Habitats of the Adonis Blue (Lysandra bellargus, Rottemburg 1775) are non-intensively used meadows between 400 and $2000 \mathrm{~m}$ asl (Gonseth 1987). The species' habitat range has been reduced on the Plateau due to intensive agriculture. The Marbled White (Melanargia galathea, L. 1758) occurs between 400 and $1800 \mathrm{~m}$ asl and prefers non-intensively used meadows.

The Large Mountain Grasshopper (Chorthippus scalaris, Fischer-Waldheim 1846) inhabits non-intensively used prairies and meadows, sun-exposed clearcuts and shrubby meadows, preferably in subalpine habitats but it is generally observed between 230 and $2230 \mathrm{~m}$ asl (Thorens and Nadig 1997).

The Common Lizard (Zootoca vivipara, Jacquin 1787) occurs in various habitats ranging between the lowlands up to $2000 \mathrm{~m}$ asl. It inhabits open forests, forest borders, and open areas in the lowlands.

Many species inventories inform about species presence only, whereas absences are rarely accounted for. Since logistic regression requires information on species absences, various methods have been suggested to develop pseudo-absences (Zaniewski et al. 2002; Engler et al. 2004; Lütolf et al. 2006).

For this study, observed presences and absences were available for bird species (Schmid et al. 1998). For the remaining species only empirically assessed presences were available, requiring the derivation of pseudo-absences. The pseudo-absences were generated based on expert habitat assessments for each species (HellerKellenberger et al. 1997, 2004). To identify likely species absences, we first eliminated areas where the species is observed or is likely to be observed following expert judgement. The remaining areas where the species is unlikely to occur were systematically sampled at a $5 \mathrm{~km}$ raster (Table 3 ).

Independent variables

\section{Climate}

Climatic variables were available as continuous surface maps, based on spatially interpolated data 
from standardised meteorological recordings and digital elevation models (DEM, $25 \mathrm{~m}$ ). We considered thermic (fost frequency, degree day sum) and hygric variables (mean monthly precipitation sum, water budget in July, and indicators for continentality (global radiation in July, Gams angle, July cloudiness) (Zimmermann and Kienast 1999; Bolliger et al. 2000).

\section{Land-use data}

Land-use data used for species habitat suitability modelling relies on an aggregation of 34 classes out of the 74 available classes in the Swiss wide land-use data (BFS 1979/85, 1992/97). The 34 classes were chosen to mirror open-land habitats for species habitat suitability modeling.

\section{Model calibration}

Selection of the set of variables to predict a species included (a) stepwise logistic regression where criteria for entry and retention thresholds were set at a level of significance of 0.05 , (b) correlation matrices where only variables with correlation coefficients of less than 0.5 were chosen.

\section{Model performance}

Confusion matrices were applied to evaluate the accuracy of the predicted versus the observed presence or absence of a species by relating the proportions of correct model predictions for presence (sensitivity) and absence (specificity) with respect to the observed data (Fielding and Bell 1997). The discriminative ability of the model to distinguish between species presence and absence was assessed using ROC plot and AUC statistics. ROC (Receiver Operating Characteristics) plots evaluate the discriminative ability of the models by plotting the sensitivity (true presences) against their equivalent (1specificity) that express false presences for all thresholds (Fielding and Bell 1997). The AUC value provides a single measure of overall model accuracy that is independent of a cut-off threshold (Deleo 1993). AUC ranges between 0.5 (no improvement in determining event presence/ absence in comparison with chance) and 1 (high model improvement with respect to chance). We applied a modified version of the AUC value, the Gini coefficient (Copas 1999). Values range between 0 and 1 , where 0 indicates no prediction success and 1 indicates high prediction success for both presence and absence.

Ideally, an independent data set is used to test a model's predictive ability. In the absence of independent data sets, alternative methods are applied, e.g., a 10 fold cross-evaluation (Verbyla and Litvaitis 1989). The original data set was randomly split into 10 data subsets of roughly equal size. Then a logistic model was estimated from $9 / 10$ of the data and applied to the remaining $1 / 10$. The procedure was repeated for all 10 data subsets to subject all data points to projections of a quasi independently estimated model.

The predictive abilities of these models was then assessed by AUC' ${ }_{\text {eval }}$ (mean and standard deviation) and compared to the predictions originating from the full calibration data set (AUC' ${ }_{\text {cal }}$ ). AUC' ${ }_{\text {eval }}$ was calculated using SimTest (Zimmermann 2001).

Species habitat distributions under land-use change scenarios

We mapped the highest decile (upper 10\%, core habitat) of species occurrence to identify sensitive areas to land-use change. The resulting species core habitat maps were then spatially intersected with the scenarios. The expected scenario-induced shifts were measured as the difference of the potential future area of the core habitat in comparison to the core habitat occupied in 1997. Gains are assessed for the expansion of the habitat (i.e., more pixels occupy suitable habitat for the species), whereas losses are reported if the core habitats under the scenarios deteriorated relative to 1997 (i.e., conversion to closed forest, scrub, intensive land-use). Gains and losses are reported in $\%$ pixel habitat gain or habitat loss. For example, an increase in forested pixels is considered negative for $S$. rubetra, which requires open-land habitats, whereas an increase in non-intensively 
used open-land pixels is evaluated as habitat gains.

\section{Results}

Land-use change scenarios

As at 1997 (Fig. 4a), forests prevail in mountainous areas of Switzerland (Northern, Central, Southern Alps, Fig. 1), whereas the valleys and the Plateau are intensively used (agriculture, settlements). Non-intensive land-use is observed in the Jura mountains, Northern pre-Alps, and at higher elevations of the Central and Southern Alps (Fig. 4a).

The business as usual scenario would not significantly change the spatial distribution of land-use classes compared to 1997, except for valley bottoms in the southern part of the Alps which would transform from intensively to nonintensively used open land (Fig. 4b; Table 2a).

The liberalisation scenario suggests spatial segregation between mountains and lowlands: intensive land-use would prevail in the lowlands and valley bottoms of the Alps (Fig. 4c, Table 2b, c). Areas at higher elevations (Northern, Central, Southern Alps) would become forested, reducing open forest, scrub, and particularly non-intensively used open-land (Fig. 4c, Table 2c).

The lowered agricultural production scenarios represent a moderate to strong increase in nonintensive open-land (Fig. 4d, e, Table 2d, e). Both scenarios suggest the conversion of intensive to non-intensive open land, particularly in the lowlands (Fig. 4d, e, Table 2d, e). Mountain areas would be dominated by scrub and forests (Table 2d, e), whereas non-intensively used open-land in high elevations would decrease only slightly.

The overall changes in scenario-based landscape composition as quantified by landscape metrics indicate fewer patch numbers, larger patch sizes and lower landscape-pattern diversity for the business as usual and the liberalisation scenario compared to the 1997 landscape (Fig. 5a-c). Higher patch numbers, smaller patch sizes and higher landscape-pattern diversity suggest a more complex landscape composition for the lowered agricultural production scenarios (Fig. 5a-c). Under the liberalisation scenario the landscape would be spatially more aggregated, whereas the lowered agricultural production scenarios show disaggregated landscapes compared to 1997 (Fig. 5d). Thus, the lowered agricultural production scenarios exhibit structurally the most diverse and least aggregated landscape compared to 1997.

Species habitat suitability models: performance

The model's discriminative abilities between species presence and absence as measured by the AUC ranges between 0.81 and 0.96 (Table 4), indicating that all models are good predictors for any threshold for species presence/absence. Tests for the model's predictive ability show that mean and standard deviation for AUC values from 10 fold cross-validation are statistically reproducible and compare well to the values obtained from the initial model calibration (Table 4).

Species habitat distributions under land-use change scenarios

Effects of the business as usual scenario on species habitats are generally minor. For most species, habitat gains and losses are approximately levelled out, except for S. rubetra and E. aethiops for which habitat gains are slightly higher than losses (Table 5). For A. arvensis, overall losses exceed gains (Table 5). Considering the spatial effect of the business as usual scenario for all seven species, habitat gains are observed primarily along valley bottoms in the southern, northern and central Alps (Fig. 6a). Habitat losses are observed for higher elevations in the Jura mountains, Central and Southern Alps, and for hilly regions on the Plateau (Fig. 6a).

Effects of the liberalisation and the lowered agricultural production scenarios are severe and may lead to significant habitat changes of the species with habitat reductions for all species (Table 5). Some species (L. vivipara, S. rubetra, M. galathea, L. bellargus, C. scalaris) may lose 

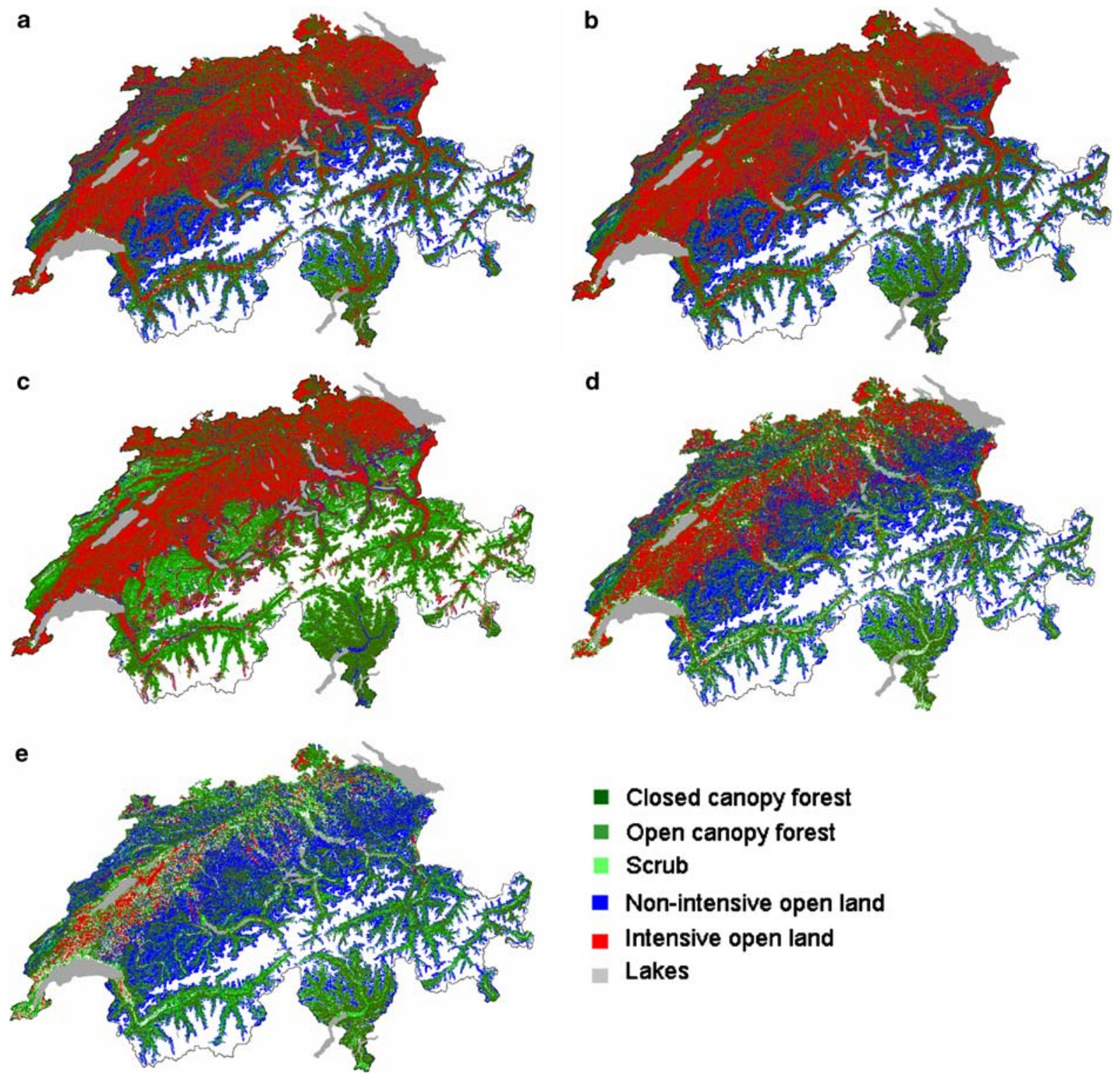

Fig. 4 Scenarios of land-use change: (a) land-use at 1997, (b) business as usual, (c) liberalisation, (d) lowered agricultural production (moderate), (e) lowered agricultural production (strong)

$33-59 \%$ of their 1997 habitat potentials (Table 5). For liberalisation, habitat losses are observed across the whole country (Fig. 6b). Habitat gains $(0.7-10 \%)$ are very minor (Table 5) and located in mountain valley bottoms and on the Plateau (Fig. 6b).

The moderately and strongly lowered agricultural production scenarios both favour open-land habitats, particularly along the northern Alps, the Jura mountains, and on the Plateau (Fig. 6c, d;
Table 5) where increases of non-intensive openland habitats (up to $41 \%$ ) are observed. The lowered agricultural production scenarios indicate that most species (S. rubetra, A. arvensis, L. vivipara, M. galathea, L. bellargus, C. scalaris) experience habitat gains between 12 and $41 \%$ for a strongly lowered agricultural production scenario. E. aethiops shows a comparable trend in comparison to the other species. However, the overall gains amount to only $7 \%$. Habitat losses 

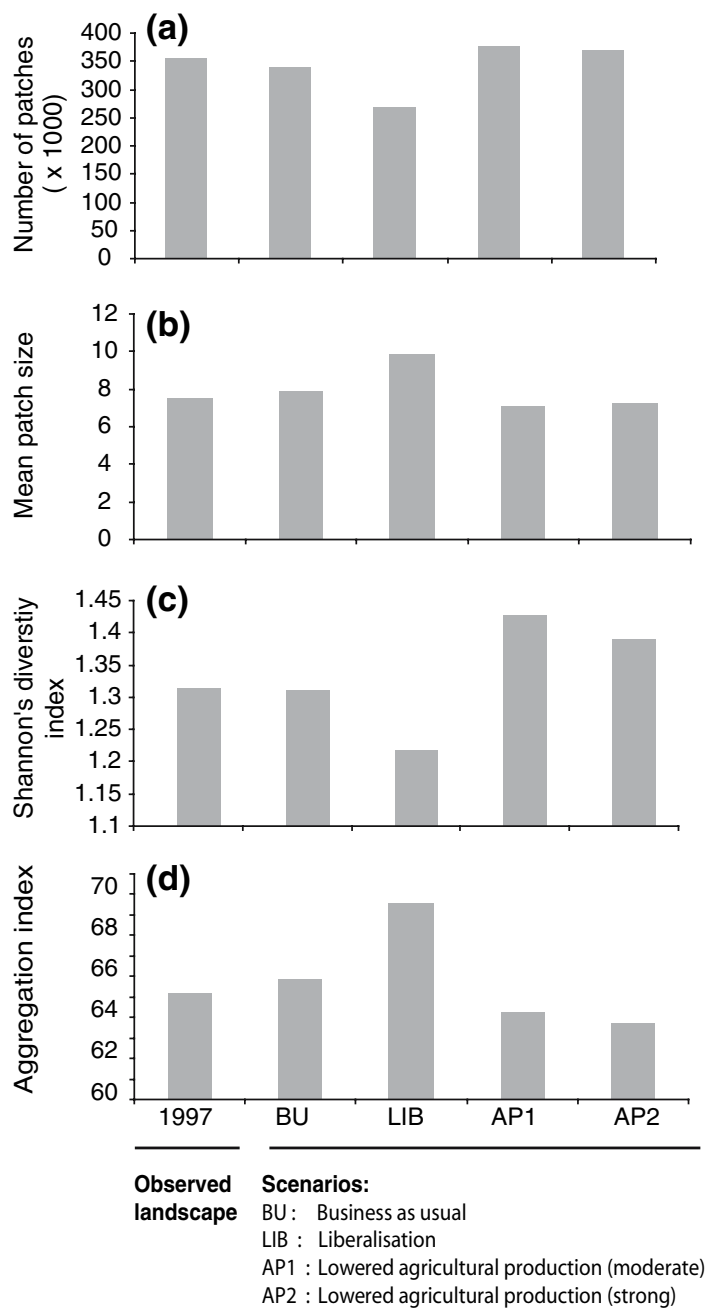

Fig. 5 Quantifying effects of land-use change with landscape metrics

are observed in parts of the Jura mountains and the Central and Southern Alps, where spontaneous reforestation due to depopulation remains likely (Fig. 6c, d, Table 5).
The magnitude of habitat gains and losses for individual geographical areas show that considerable habitat losses are observed under the liberalisation scenario for the Northern Alps where a large proportion of originally nonintensively used open-land is converted to forest (Figs. 6b, 7a). Major habitat gains are to be expected for all species on the Plateau under the lowered agricultural scenarios production scenario where considerable conversion of intensively used to non-intensively open-land is observed (Fig. 6c, d, 7b).

\section{Discussion}

\section{Land-use change scenarios}

Large proportions of key open-land habitat for species diversity in agriculturally favourable regions in Europe are of anthropogenic origin. Their maintenance relies primarily on human intervention which itself depends on political decisions and socio-economic processes, stressing the necessity to include socio-economic expert judgement in landscape-relevant research (Wu and Hobbs 2002; Wu 2006). The land-use change scenarios developed here include research methods and findings from social and ecological sciences, designed to assess developments of future landscapes under agricultural change. The business as usual scenario extrapolates land-use changes observed between 1985 and 1997 into the future. This moderate scenario is contrasted by more extreme scenarios (liberalisation, lowered agricultural production). Although these scenarios remain unlikely future landscape realisations, they are useful to

Table 4 Model performance: calibrated (cal), evaluated (eval, $n=10$. Means, with categorised standard deviation: ${ }^{+}<0.01$, $\left.{ }^{++} 0.01-0.1,{ }^{+++}>0.1\right)$

\begin{tabular}{|c|c|c|c|c|c|c|c|}
\hline \multirow{2}{*}{$\begin{array}{l}\text { Model } \\
\text { performance }\end{array}$} & \multicolumn{7}{|l|}{ Species } \\
\hline & $\begin{array}{l}\text { Saxicola } \\
\text { rubetra }\end{array}$ & $\begin{array}{l}\text { Alauda } \\
\text { arvensis }\end{array}$ & $\begin{array}{l}\text { Lacerta } \\
\text { vivipara }\end{array}$ & $\begin{array}{l}\text { Erebia } \\
\text { aethiops }\end{array}$ & $\begin{array}{l}\text { Melanargia } \\
\text { galathea }\end{array}$ & $\begin{array}{l}\text { Lysandra } \\
\text { bellargus }\end{array}$ & $\begin{array}{l}\text { Chorthippus } \\
\text { scalaris }\end{array}$ \\
\hline $\mathrm{AUC}_{\mathrm{cal}}$ & 0.84 & 0.81 & 0.96 & 0.94 & 0.96 & 0.94 & 0.95 \\
\hline $\mathrm{AUC}_{\mathrm{cal}}^{\prime}$ & 0.68 & 0.61 & 0.92 & 0.88 & 0.92 & 0.88 & 0.9 \\
\hline $\mathrm{AUC}_{\mathrm{eval}}$ & $0.84^{+}$ & $0.8^{++}$ & $0.98^{+}$ & $0.98^{+}$ & $0.91^{+}$ & $0.93^{++}$ & $0.95^{+}$ \\
\hline AUC' & $0.68^{+}$ & $0.6^{+++}$ & $0.76^{+}$ & $0.96^{+}$ & $0.83^{+}$ & $0.86^{+++}$ & $0.9^{+}$ \\
\hline
\end{tabular}


Table 5 Gains and losses of species habitats (\% pixels compared to 1997)

\begin{tabular}{|c|c|c|c|c|}
\hline & $\begin{array}{l}\text { Business } \\
\text { as usual }\end{array}$ & $\begin{array}{l}\text { Libera- } \\
\text { lisation }\end{array}$ & $\begin{array}{l}\text { Lowered } \\
\text { agricultural } \\
\text { production } \\
\text { (moderate) }\end{array}$ & $\begin{array}{l}\text { Lowered } \\
\text { agricul } \\
\text { tural } \\
\text { production } \\
\text { (strong) }\end{array}$ \\
\hline \multicolumn{5}{|c|}{ (a) Saxicola rubetra } \\
\hline Gains & 2.04 & 6.57 & 13.0 & 20.31 \\
\hline Losses & 1.81 & 34.3 & 2.8 & 2.8 \\
\hline \multicolumn{5}{|c|}{$\begin{array}{l}\text { (b) Alauda arvensis } \\
\text { Land-use }\end{array}$} \\
\hline Gains & 0.15 & 0.68 & 2.07 & 12.0 \\
\hline Losses & 0.51 & 4.45 & 0.97 & 0.8 \\
\hline \multicolumn{5}{|c|}{ (c) Lacerta vivipara } \\
\hline Gains & 2.91 & 10.29 & 21.26 & 39.46 \\
\hline Losses & 3.00 & 59.23 & 4.65 & 4.66 \\
\hline \multicolumn{5}{|c|}{ (d) Erebia aethiops } \\
\hline Gains & 1.7 & 4.09 & 6.08 & 7.2 \\
\hline Losses & 1.3 & 41.5 & 2.07 & 2.0 \\
\hline \multicolumn{5}{|c|}{ (e) Melanargia galathea } \\
\hline Gains & 3.05 & 10.58 & 21.43 & 41.1 \\
\hline Losses & 3.04 & 53.15 & 4.71 & 4.71 \\
\hline \multicolumn{5}{|c|}{ (f) Lysandra bellargus } \\
\hline Gains & 2.17 & 9.13 & 19.03 & 32.50 \\
\hline Losses & 2.15 & 34.06 & 3.33 & 3.34 \\
\hline \multicolumn{5}{|c|}{ (g) Chorthippus scalaris } \\
\hline Gains & 1.87 & 5.84 & 11.00 & 17.82 \\
\hline Losses & 1.94 & 33.37 & 3.00 & 2.99 \\
\hline
\end{tabular}

benchmark development extremes to quantify potential effects on the landscape. Caveats include that the temporal dimension of the scenarios cannot explicitly be accounted for. Estimations as to when the respective landscape states may be reached range from approximately 20 to 30 years for the business as usual scenario, 30-50 years for the lowered agricultural production scenarios, and between 100 and 200 years for the liberalisation scenario.

Results show that likely consequences of agricultural change are spatially segregated with lower reforestation tendencies in the lowlands due to favourable socio-economic, topographic and climatic conditions, which foster agricultural land-use. Strong reforestation tendencies and loss of open-land are more pronounced in mountainous areas (Jura mountains, Alps).

Scenario-derived changes in landscape composition and configuration were assessed statistically by landscape metrics, which measure pixel densities and distributions numerically. The landscape changes indicate that the lowered agricultural production scenarios would exhibit highest compositional and configuration diversity, whereas the liberalisation scenario may lead to aggregated and less diverse landscapes with large patches and increased homogenisation. Use and limitation of landscape metrics have been discussed in detail elsewhere (Gustafson 1998; McGarigal et al. 2002; $\mathrm{Li}$ and $\mathrm{Wu}$ 2004). In general, landscape metrics are considered valuable tools to describe statistical landscape characteristics, whereas details on the ecological implications for organisms cannot be easily assessed.

Scale effects have been identified to be of great relevance in landscape research (Wu and Hobbs 2002) and various aspects of scale have been studied intensively (Wu 1999, 2004; Wu et al. 2002). It has been stated that the relevant spatial pattern is revealed only if the scale of analysis approaches the operational scale of the phenomenon under study (Wu 1999, 2004) referring to the dependence of spatial pattern on the scale of observation and analysis. In this study, both the scale of analysis and the operational scale of the phenomenon (land-use, species distributions) is the landscape scale $\left(41,000 \mathrm{~km}^{2}\right)$. This ensures agreement between the scale of analysis and the operational scale of the phenomenon (land-use, species distributions) as required for the detection of the relevant patterns in a multi-scale landscape.

The drivers of the land-use change scenarios, however, were selected independently of the spatial scale (scale invariant) so that they are important for both, the local and the landscape scale. Drivers include e.g., depopulation tendencies, farm abandonment (Soliva et al. accepted). In a qualitative acceptability assessment the localscale social relevance of the scenarios was tested. Local visualisations of the land-use change scenarios were presented to stakeholders in a mountain area. Although less labour intensive and low-cost, stakeholders rejected the liberalisation scenario due to loss of landscape quality. At the same time, stakeholders did not accept the social, economic and cultural price of a scenario that puts conservation and biodiversity first although increased biodiversity was considered 

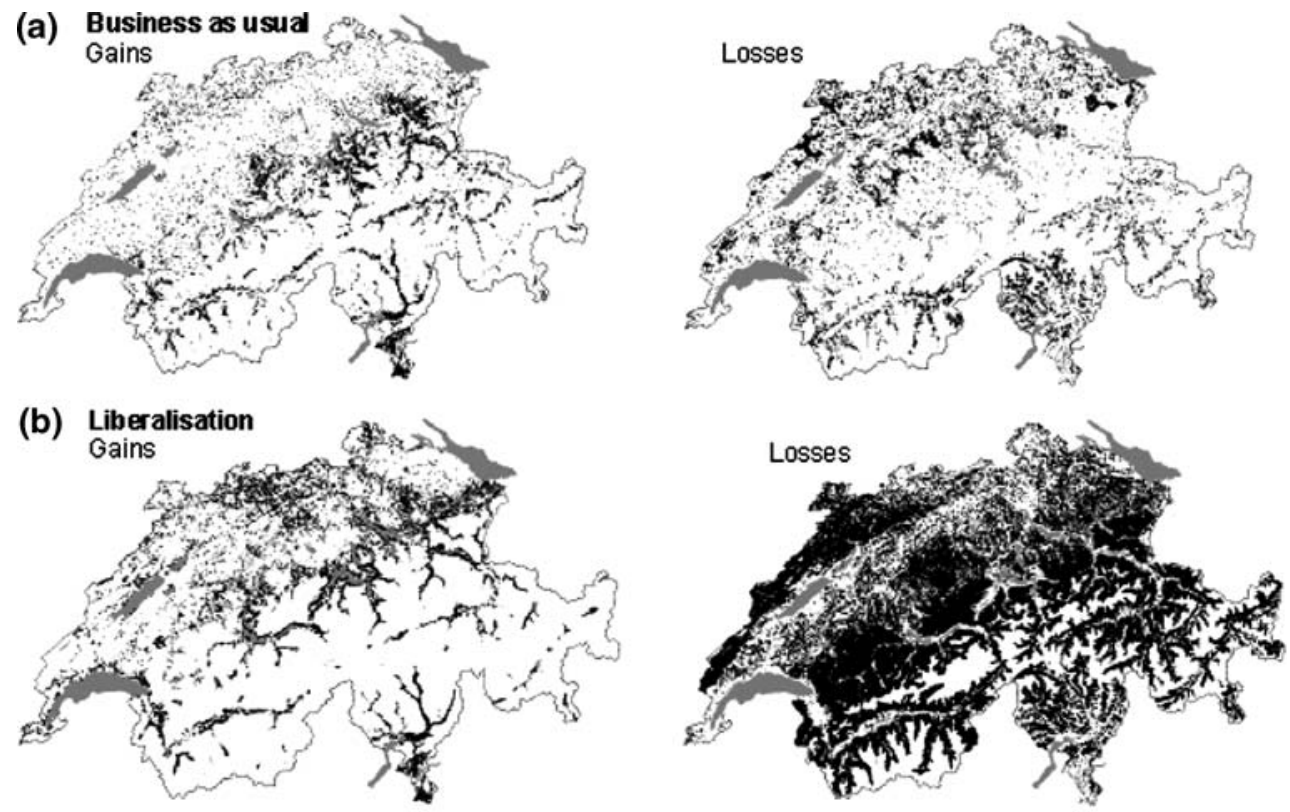

(c) Lowered agricultural production (moderate)
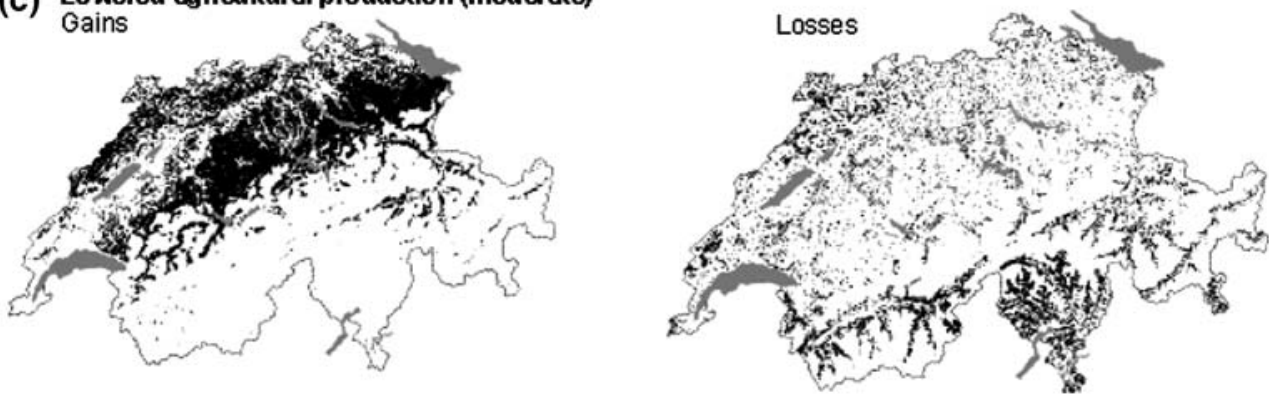

(d) Lowered agricultural production (strong)

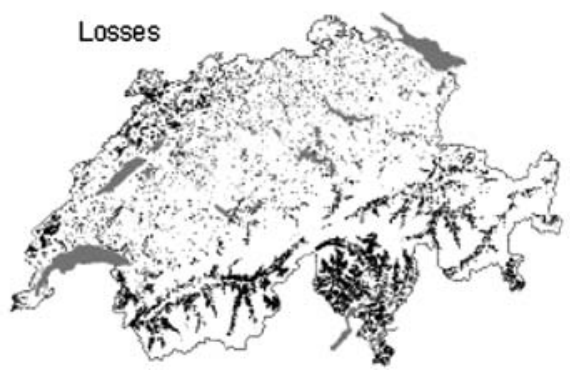

Fig. 6 Expected spatial sensitivity of cumulative habitat gains/losses for seven open-land species

valuable and although stakeholders liked the resulting landscapes. Instead, stakeholders preferred the landscapes resulting from the business as usual scenario, which resembles the current landscape and ensures continued open-land management. A future development trajectory, which favours biodiversity, but is not supported by local stakeholders, is thus no viable option.
Species habitat distributions under land-use change scenarios

Landscape patterns have direct implications for biodiversity and conservation (Lindbladh 1999; Haines-Young et al. 2003) since landscape structure influences the movement of organisms and energy. Because the intensity of land use 
Fig. 7 Expected magnitude of change in biogeographic regions for seven open-land species
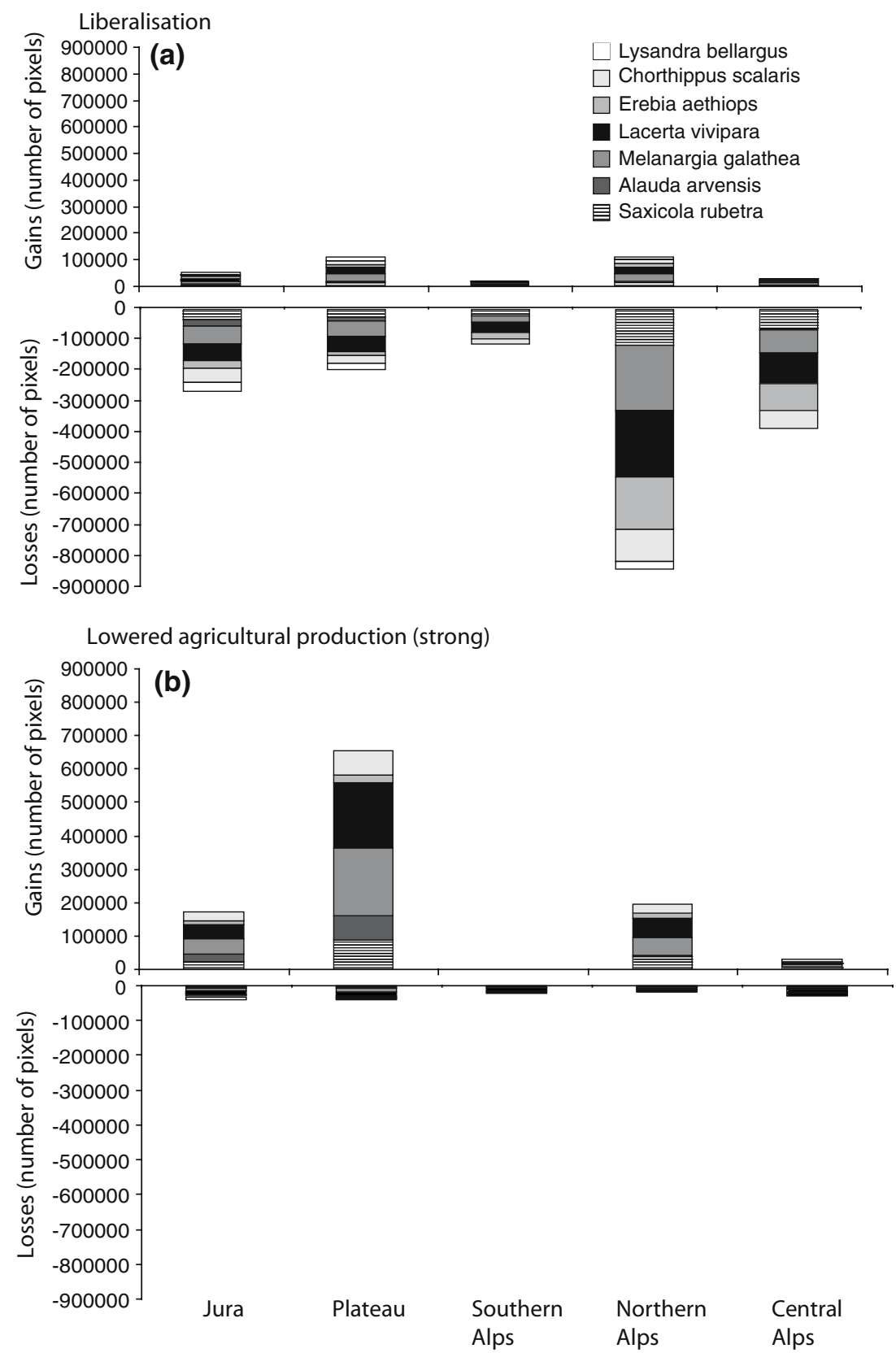

management can be directly related to the pattern in agricultural landscapes (Margalef 1994), changes in land-use patterns caused by land abandonment have been identified as major drivers of decline in species diversity (Labaune and Magnin 2002; Dullinger et al. 2003b). Loss of open-land habitats, mainly non-intensive meadows and pastures, is considered a threat to species diversity, particularly to rare and declining spe- cies (Labaune and Magnin 2002; Dirnböck et al. 2003; Laiolo et al. 2004). Results from our study are in line with the above findings although here we focus to assess cumulative effects of selected open-land species rather than overall biodiversity. Under a liberalisation scenario with strong reforestation tendencies, open-land species habitats suffer reductions up to $59 \%$ of their 1997 habitat potential. Contrarily, the lowered agricultural 
production scenario increases potential habitat areas between up to $41 \%$. In addition, a scenarioinduced spatial segregation of the sensitive core habitat areas is observed. Whereas areas for habitat gains are primarily located on the Plateau and the Northern Alps, losses of open-land species habitats are observed for the whole country, but particularly for mountainous areas (Jura, Alps). Such spatial segregation of the magnitude of land-use change has been observed for a variety of other mountainous areas (Brown 2003).

The method applied to assess potential effects of land-use change due to agricultural decline relies on species habitat suitability models. The models exhibit satisfying model performance. It has been claimed that predicting species responses to habitat changes is a challenges for ecologists (Travis 2002; Thuiller et al. 2004). Among methods, predictive modelling has been an important tool to assess management or conservation strategies for biota e.g., for inconspicuous species (Edwards et al. 2005), or biota under changing environments (Dirnböck et al. 2003; Araujo et al. 2004). Among predictive models, logistic regression is well established and has been applied to a broad variety of research topics and conservation issues (Bolliger et al. 2000; Guisan and Hofer 2003; McKenzie et al. 2003). It has been claimed that a broad variety of approaches are required to successfully identify ecological complexity (Loehle 2004). Thus, an approach which predicts species distributions as a function of climatic and land-use information may over- or under-predict species habitats since dynamic biotic interactions, adaptive genetic variation, dispersal and migration cannot be accounted for with such a parsimonious method (Hannah et al. 2002; Hampe 2004). However, since details on species-specific lifehistory attributes or environment are not usually available for large spatial scales, the parsimonious regression approach may be seen as a trade-off between predictions at large scales and data availability which holds true for landscape scales where strong (environmental) gradients drive the biotic patterns as it is the case for Switzerland (Bolliger et al. 2000; Thuiller et al. 2003). Thus, habitat models from regressions can provide a suitable approach to identify potential impacts of landscape change on species habitats. Use and limitations of species distribution modelling have been discussed in detail elsewhere (e.g., Guisan and Zimmermann 2000; Hampe 2004; Segurado and Araujo 2004; Guisan and Thuiller 2005) and will thus not be repeated here.

\section{Conclusions}

The study shows that it is crucial for open-land species that agricultural and conservation policy allow for non-intensively used open-land habitats to be maintained and managed in a sustainable way. We suggest that the lowered agricultural production scenario is most beneficial for openland species however, its social acceptability is limited due to high costs. Combinations of the business as usual and lowered agricultural production scenario would be adequate: farmers would continue to receive public support, which is more tightly linked to current regionally adapted agri-environmental schemes focussing on the non-intensive use the land. Combining ecological analysis with socio-economic investigations of stakeholder's scenario-assessments may thus provide useful input for future regional development and conservation, facilitating an integrated approach to biodiversity conservation.

Acknowledgements Many thanks to the Centre Suisse de Cartographie de la Faune, Neuchâtel (Simon Capt, Yves Gonseth) for their expert advice and for providing the species data. We would also like to thank Thomas Niemz for kindly conducting some of the GIS analyses. This research was supported by the BioScene project funded by the European Union (EVK2-2001-00354).

\section{References}

Araujo MB, Cabeza M, Thuiller W, Hannah L, Williams $\mathrm{PH}$ (2004) Would climate change drive species out of reserves? An assessment of existing reserve-selection methods. Glob Change Biol 10:1618-1626

Bakker J (1989) Nature management by grazing and cutting. Kluwer Academic Publishers, London

Bätzig W (1996) Landwirtschaft im Alpenraum unverzichtbar, aber zukunftslos? Eine alpenweite Bilanz der aktuellen Probleme und der möglichen Lösungen. In: Bätzig W 
(ed) Landwirtschaft im Alpenraum - unverzichtbar, aber zukunftslos? Europäische Akademie Bozen, Fachbereich Alpine Umwelt, Blackwell, Wien, pp 9-11

BFS (1979/85) Arealstatistik, Bundesamt für Statistik, Servicestelle GEOSTAT, CH-Neuchatel

BFS (1992/97) Arealstatistik, Bundesamt für Statistik, Servicestelle GEOSTAT, CH-Neuchatel

BLW (2003) Verordnungspaket 2007. Ausführungsbestimmungen zur Agrarpolitik 2007. Informationsveranstaltung vom 5.12.2003, Bundesamt für Landwirtschaft, Bern

BLW (2004) Agrarbericht 2004, Bundesamt für Landwirtschaft, Bern

Bolliger J, Kienast F, Zimmermann NE (2000) Risks of global warming on montane and subalpine forests in Switzerland. Region Environ Change 1:99-111

Brown DG (2003) Land use and forest cover on private parcels in the Upper Midwest USA, 1970 to 1990. Landscape Ecol 18:777-790

Copas J (1999) The effectiveness of risk scores: the logit rank plot. J Roy Stat Soc Ser C-Appl Stat 48:165-183

Deleo JM (1993) Receiver operating characteristic laboratory (ROCLAB): software for developing decision strategies that account for uncertainty. Proceedings of the first international symposium on uncertainty modelling and analysis. IEEE, Computer Society Press, College Park, MD, pp 318-325

Dirnböck T, Dullinger S, Grabherr G (2003) A regional impact assessment of climate and land-use change on alpine vegetation. J Biogeogr 30:401-417

Dullinger S, Dirnböck T, Grabherr G (2003a) Patterns of shrub invation into high mountain grasslands of the Northern calcareous Alps, Austria. Arct Antarct Alp Res 35:434-441

Dullinger S, Dirnböck T, Greimler S, Grabherr G (2003b) A resampling approach to evaluate effects of summer farming on subalpine plant species diversity. J Veg Sci $14: 243-252$

Edwards TC, Cutler R, Zimmermann NE, Geiser L, Alegria J (2005) Model-based stratification for enhancing the detection of rare ecological events. Ecology 86:1081-1090

Engler R, Guisan A, Rechsteiner L (2004) Predicting the distribution of rare and endangered species from occurrence and pseudo-absence data. J Appl Ecol 41:263-274

FAT (2002) Zentrale Auswertung von Buchhaltungsdaten, Tänikon

Fielding AH, Bell JF (1997) A review of methods for the assessment of prediction errors in conservation presence/absence models. Environ Conserv 24:38-49

Flury C (2002) Zukunftsfähige Landwirtschaft im Alpenraum, Diss. ETH Nr. 14528: Zürich

Gonseth Y (1987) Verbreitungsatlas der Tagfalter der Schweiz (Leptidoptera, Rhopalocera), 6. Documenta Faunistica Helvetica

Guisan A, Hofer U (2003) Predicting reptile distributions at the mesoscale: relation to climate and topography. J Biogeogr 30:1233-1243

Guisan A, Thuiller W (2005) Predicting species distributions: offering more than simple habitat models. Ecol Lett 8:993-1009
Guisan A, Zimmermann NE (2000) Predictive habitat distribution models in ecology. Ecol Model 135:147-186

Gustafson EJ (1998) Quantifying landscape spatial pattern: what is the state of the art? Ecosystems 1:143-156

Haines-Young R et al (2003) Changing landscapes, habitats and vegetation diversity across Great Britain. J Environ Manage 67:267-281

Hampe A (2004) Bioclimate envelope models: what they detect and what they hide. Global Ecol Biogeogr 13:469-476

Hannah L et al (2002) Conservation of biodiversity in a changing climate. Conserv Biol 16:264-268

Heller-Kellenberger I, Kienast F, Obrist M, Walter T (1997) Räumliche Modellierung der potentiellen faunistischen Biodiversität mit einem Expertensystem. Informationsblatt des Forschungsbereiches Landschaft 36

Heller-Kellenberger I, Kienast F, Obrist MK, Walther TA (2004) Biodiversity hostspots-modeling potential faunistic biodiversity with a spatially explicit expert system. Swiss Federal Research Institute WSL

Jenny M (1990) Populationsdynamik der Feldlerche Alauda arvensis in einer intensiv genutzten Agrarlandschaft. J Ornithol 131:241-265

Jepsen JU, Topping CJ, Odderskaer P, Andersen PN (2005) Evaluating consequences of land-use strategies on wildlife populations using multiple-species predictive scenarios. Agric Ecosyst Environ 105(4):581-594

Labaune C, Magnin F (2002) Pastoral management vs. land abandonment in Mediterranean uplands: impact on snail communities. Global Ecol Biogeogr Lett 11:237-245

Laiolo P, Dondero F, Ciliento E, Rolando A (2004) Consequences of pastoral abandonment for the structure and diversity of the alpine avifauna. J Appl Ecol 41:294-304

Li H, Wu J (2004) Use and misuse of landscape indices. Landscape Ecol 19:389-399

Lindbladh M (1999) The influence of former land-use on vegetation and biodiversity in the boreo-nemoral zone of Sweden. Ecography 22:485-498

Loehle C (2004) Challenges of ecological complexity. Ecol Complexity 1:3-6

Lundström-Gilliéron C, Schläpfer R (2003) Hare abundance as an indicator for urbanisation and intensification of agriculture in Western Europe. Ecol Model 168:283-301

Lütolf M, Kienast F, Guisan A (2006) Strategies to improve species distribution model performance using occurrence data. J Appl Ecol 43:802-815

Mack G, Ferjani A (2002) Auswirkungen der Agrarpolitik (2007) Modellrechnungen für den Agrarsektor mit Hilfe des Prognosesystems SILAS, FAT, Tänikon

Margalef R (1994) Dynamic aspects of diversity. J Veg Sci 5:451-456

McCracken DI, Bignal EM (1998) Applying the results of ecological studies to land-use policies and practices. J Appl Ecol 35:961-967

McGarigal K, Cushman SA, Neel MC, Ene E (2002) FRAGSTATS: Spatial pattern analysis program for categorial maps. Computer software program 
produced by the authors at the University of Massachusetts, Amherst, MA, USA. http://www.umass.edu/ landeco/research/fragstats/fragstats.html

McKenzie D, Peterson DW, Peterson DL, Thornton PE (2003) Climatic and biophysical controls on conifer species distributions in mountain forests of Washington State, USA. J Biogeogr 30:1093-1108

Meeus J, Van Der Ploeg JD, Wijermans M (1991) Changing agricultural landscapes in Europe: continuity, deterioration or rupture? IFLA conference, Rotterdam, The Netherlands

Moreira F et al (2005) Effects of field management and landscape context on grassland wintering birds in Southern Portugal. Agricult Ecosyst Environ 109:59-74

Muller M, Spaar R, Schifferli L, Jenni L (2005) Effets of changes in farming of subalpine meadows on a grassland bird, the whinchat (Saxicola rubetra). J Ornithol 146(1):14-23

OECD (2002) Agricultural Policies in OECD countries. Monitoring and Evaluation, Paris

Orlowski G (2004) Abandoned cropland as a habitat for the Whinchat Saxicola rubetra in SW Poland. Acta Ornithologica 39:59-66

Sager J, Finger A (1992) Die Bodennutzung der Schweiz. Arealstatistik 1979/85. Kategorienkatalog. 002-8502, Bundesamt für Statistik, Bern. 191 pp

Schmid H, Luder R, Naef-Daenzer B, Graf R, Zbinden N (1998) Schweizer Brutvogelatlas. Verbreitung der Brutvögel in der Schweiz und im Fürstentum Liechtenstein 1993-1996. Schweizerische Vogelwarte, Sempach

Segurado P, Araujo MB (2004) An evaluation of methods for modelling species distributions. J Biogeogr 31:1555-1568

Söderström B, Svensson B, Vessby K, Glimskär A (2001) Plants, insects, and birds in semi-natural pastures in relation to local habitat and landscape factors. Biodivers Conserv 10:1839-1863

Soliva R, Rønningen K, Bella I, Bezak P, Cooper T, Flø BE, Marty P, Potter C. Envisioning Upland Futures: Stakeholder responses to scenarios for Europe's mountain landscapes. J Rural Stud (accepted)

Statistisches Jahrbuch der Schweiz (1997) 104. Verlag Neue Zürcher Zeitung, Zürich

Thorens P, Nadig A (1997) Verbreitungsatlas der Orthopteren der Schweiz
Thuiller W, Araujo MB, Lavorel S (2003) Generalized models vs. classification tree analysis: predicting spatial distributions of plant species at different scales. J Veg Sci 14:669-680

Thuiller W, Araujo MB, Lavorel S (2004) Do we need land-cover data to model species distributions in Europe? J Biogeogr 31:353-361

Tilman D et al (2001) Forecasting agriculturally driven global environmental change. Science 292:281-284

Travis JMJ (2002) Climate change and habitat destruction: a deadly anthropogenic cocktail. Proc R Soc Lond B 270:467-473

Tucker GM, Heath MF (1994) Birds in Europe: their conservation status. Series No. 3. BirdLife International, Cambridge

van der Vaart JHP (2005) Towards a new rural landscape: consequences of non-agricultural re-use of redundant farm buildings in Friesland. Landscape Urban Plan 70:143-152

Verbyla DL, Litvaitis JA (1989) Resampling methods for evaluation classification accuracy of wildlife habitat models. Environ Manage 13:783-787

Weibel U (2004) Bauern, die Biodiversität produzieren. Ornis 2:4-8

Wu J (1999) Hierarchy and scaling: extrapolating information along a scaling ladder. Int $\mathrm{J}$ Remote Sensing 25:367-380

Wu J (2004) Effects of changing scale on landscape pattern analysis: scaling relations. Landscape Ecol 19:125-138

Wu J (2006) Landscape ecology, cross-disciplinarity, and sustainability science. Landscape Ecol 21:1-4

Wu J, Hobbs R (2002) Key issues and research priorities in landscape ecology: an idiosyncratic synthesis. Landscape Ecol 17:355-365

Wu J, Shen W, Sun W, Tueller PT (2002) Empirical patterns of the effects of changing scale on landscape metrics. Landscape Ecol 17:761-782

Zaniewski AE, Lehmann A, Overton JM (2002) Predicting species spatial distributions using presence-only data: a case study of native New Zealand ferns. Ecol Model 157:261-280

Zimmermann NE (2001) SimTest. http:/www.wsl.ch/staff/ niklaus.zimmermann/programs/fort10_1.html, WSL, Birmensdorf

Zimmermann NE, Kienast F (1999) Predictive mapping of Alpine grasslands in Switzerland: species versus community approach. J Veg Sci 10:469-482 